\title{
Vaccine and Cancer Therapy for Genitourinary Tumors
}

\author{
Robert J. Amato and Mika Stepankiw \\ University of Texas Health Science Center at Houston/ \\ Memorial Hermann Cancer Center,
}

USA

\section{Introduction}

Immunotherapy for human cancer has remained in the experimental stage for more than a century. This lengthy duration reflects as much the scope of failures in the area as it does the continuous and remarkable expansion of understanding of immune responses and hosttumor interaction. Immunotherapy for human cancer has largely focused on immunization with peptides or whole antigens, intact tumor cells, or dendritic cells pulsed with antigenic peptides isolated from cancers; adoptive transfer of T-cells or immunomodulatory strategies such as the use of blocking antibody to cytotoxic T-lymphocyte antigen-4.

Currently, cytokines have been described and there is much more knowledge of how the immune system functions, in particular, how cellular immune responses are generated and how peptides can be presented by class I or II molecules. This knowledge has led to the peptide approach to tumor immunotherapy. Dendritic cells have emerged and have been shown to play an essential role in generating immune responses in patients with cancer. Various other methods have also applied for the generation of cell-free vaccines. In addition, there are several methods of measuring cellular immunity - cytotoxic T-lymphocytes, T-cell proliferation, flow cytometry, ELISPOT, and major histocompatibility complex class I/class II tetramers to follow immune activation. Currently, there are two vaccines approved for genitourinary cancers (Table 1) with a few others in late stage clinical trials. This chapter reviews the development of vaccine cancer immunotherapy in genitourinary cancers.

\begin{tabular}{|c|c|c|c|}
\hline Cancer & Drug & Interaction & Status \\
\hline $\begin{array}{l}\text { Renal Cell } \\
\text { Carcinoma }\end{array}$ & Vitespen & $\begin{array}{l}\text { Heat shock proteins from } \\
\text { autologous cells }\end{array}$ & $\begin{array}{l}\text { Approved by Russia in } \\
2008 \text {, on U.S. fast track for } \\
\text { approval }\end{array}$ \\
\hline Prostate & Sipuleucel-T & Dendritic Cells & Approved in 2010 \\
\hline Prostate & PROSTVAC & Prostate-specific antigen & Seeking FDA approval \\
\hline Bladder & OncoTice & Bacille Calmette-Guerin & Approved \\
\hline
\end{tabular}

Table 1. Approved Genitourinary Cancer Vaccines 


\section{Prostate cancer}

As the most common noncutaneous malignancy to affect men and the second leading cause of cancer-related deaths in men in the United States, prostate cancer is expected to afflict approximately one in six men during their lifetime (Waeckerle-Men, Allmen, Fopp, et al., 2009). Prostatectomy and radiation therapy has been successful in approximately $80 \%$ of patients who are diagnosed to be in the early stages of prostate cancer. If a patient fails these early stage therapies or has advanced stages of prostate cancer, he undergoes hormonal therapies. Unfortunately, not all hormonal therapy is effective in eliminating malignant cells, and eventually all patients reach castration-resistant prostate cancer levels. For these patients, there are a limited number of successful treatment options, and all of these treatments are considered palliative with a median survival of less than two years (Waeckerle-Men, Allmen, Fopp, et al., 2009). The approval of docetaxel by the Food and Drug Administration in 2004 was able to extend the life expectancy of these patients by two months (Thomas-Kaskel, Zeiser, Jochim, et al., 2006). However, docetaxel is cell-cycle specific, which means that it is cytotoxic to all dividing cells and not just tumor cells. Patients who take docetaxel are likely to experience neutropenia, anemia, neuropathy, alopecia, and nail damage. Docetaxel-based therapy is not a cure as some patients fail therapy. Because of this, therapeutic strategies that offer a more favorable toxicity profile while providing more effective treatments are needed for the management of disease progression. Prostate cancer vaccines have the ability to target tumor-specific antigens while leaving healthy cells intact (Vieweg, Dannul, 2005). Currently one vaccine is approved for the treatment of prostate cancer, and a second vaccine is in the process of seeking Food and Drug Administration approval.

\subsection{Peptides and proteins}

One vaccine approach is to use peptides and proteins with or without adjuvant treatment to stimulate $\mathrm{T}$ cell activation. Many peptide and protein vaccines focus on human leukocyte antigen class I-binding prostate-specific antigens or prostate-specific membrane antigens. Often a multi-epitope, broad spectrum approach is used. Prostate-specific antigens are the most characterized antigen and thus currently the best antigen for the creation of a prostate cancer vaccine. Several trials have demonstrated prostate-specific antigen vaccines as producing an immunological response. However, the problem with prostate-specific antigen vaccines is that this antigen is a secreted protein so it is expressed on healthy cells as well as malignant cells.

Prostate stem cell antigen is expressed on more than $85 \%$ of prostate cancer specimens with these expression levels increasing with the higher Gleason scores and androgen independence (Thomas-Kaskel, Zeiser, Jochim, et al., 2006). One phase I/II study involving 12 patients receiving four vaccinations bi-weekly examined the safety of prostate stem cell antigen vaccines. No adverse reactions were observed, and six patients achieved stable disease, and median survival achieved was 22 months.

Currently, PROSTVAC is in the final stages of clinical development, seeking Food and Drug Administration approval. PROSTVAC uses a prostate-specific antigen in combination with two poxviruses and three immune enhancing molecules. One randomized, controlled, and blinded (2:1 ratio) phase II trial involving 125 patients with minimally systematic castration- 
resistant metastatic prostate cancer evaluated PROSTVAC for safety, progression free survival, and overall survival. No association to progression free survival was found in the patients receiving PROSTVAC, yet a strong association was found between overall survival and those patients receiving PROSTVAC (Kantoff, Schuetz, Blumenstein, et al., 2010). Research supports that peptide and protein vaccines may be a viable option for treating castration-resistant prostate cancer.

\subsection{Dendritic cell vaccines}

Dendritic cells have been identified as having a critical role in the induction of antitumor response as dendritic cells help present tumor-associated antigens to $\mathrm{T}$ lymphocytes. Researchers have become interested in dendritic cells because all class I or class II-restricted protein antigens must be processed by dendritic cells in order to activate the body's immune response (Banchereau, \& Steinman, 1998) and to prime and activate CD4+ and CD8+ cells. Dendritic cell vaccines have no significant adverse reactions, and an immune response against prostate-specific membrane antigen, prostate-specific antigen, prostatic acid phosphatase, and telomerase reverse transcriptase has been found in patients receiving the vaccine. More recent dendritic cell vaccine trials have adopted a multi-epitope approach to overcome malignant cells from evading the body's immune system.

Some vaccines focus on prostatic acid phosphatase antigen, an enzyme produced by the prostate that is typically only expressed on normal and malignant prostate cells (McNeel, Dunphy, Davies, et al., 2009). Preclinical murine studies using vaccines that target prostatic acid phosphatase have demonstrated an immunological response as evidenced by CD8+ activation (Johnson, Frye, Chinnasamy, et al., 2007). One phase I/IIa trial using a prostatic acid phosphatase vaccine found an increase in prostate-specific antigen doubling time and CD4+ and CD8+ proliferation with no evidence of significant adverse events cells (McNeel, Dunphy, Davies, et al., 2009).

The only prostate cancer vaccine currently holding Food and Drug Administration approval is sipuleucel-T (Provenge), which utilizes autologous dendritic cells activated with the proteins PA2024 and prostatic acid phosphatase-linked granulocyte-macrophage colony stimulating factor. One randomized trial of sipuleucel-T studied 225 patients with castration resistant prostate cancer. Patients received three intravenous infusions approximately two weeks apart, and those who received the sipuleucel-T vaccine versus the placebo demonstrated a $33 \%$ reduction in the risk of death. Overall toxicity profile was favorable and consisted mainly of grade 1 or 2 asthenia, chills, dyspnea, headache, pyrexia, vomiting, and tremor (Higano, Schellhammer, Small, 2009).

Multi-epitope dendritic cell vaccines have been under focus as a feasible approach that may generate efficient cellular antitumor response. In a phase I/II trial, six patients received a total of six dendritic cell vaccines pulsed with prostate stem cell antigen, prostatic acid phosphatase, prostate-specific membrane antigen, and prostate-specific antigen biweekly followed by a monthly booster injection. Two patients were removed to the study due to conflicting treatments or severe pyelonephritis. In the remaining patients, three showed evidence of significant antitumor response. With no side effects, this study demonstrated that using a multi-epitope approach on a dendritic cell vaccine can elicit a broad $\mathrm{T}$ cell response (Waeckerle-Men, Allmen, Fopp, et al., 2009). 
Another multi-epitope dendritic cell vaccine phase I/II randomized, single center trial studied 19 human leukocyte antigen-A2 positive patients. Patients received six vaccinations, and an immune response was found in eight of the patients with and improved prostatespecific antigen doubling time in four of those patients (Feyerabend, Stevanovic, Gouttefangeas, et al., 2009). A second dendritic vaccine trial focusing on human leukocyte antigen-positive patients used a dendritic cell vaccine in combination with prostate-specific antigens, prostate-specific membrane antigen, survivn, and prostein. Eight patients received four vaccinations bi-weekly demonstrated evidence of prostate-specific antigen response and CD8+ $\mathrm{T}$ cell activation against prostein, survivn, and prostate-specific membrane antigen with no side effects outside of local skin irritation (Fuessel, Meye, Schmitz, et al., 2006). Evidence from various research trials suggests that multi-epitope vaccines are a promising treatment option for advanced prostate cancer.

\subsection{Viral-based immunotherapy}

Using highly immunogenic viruses to express all of the cytotoxic proteins increases the visibility of malignant cells to the immune system, and $\mathrm{T}$ cells are able to target cancerspecific antigens. Finding the most beneficial tumor-associated antigens to target has been difficult for the development of effective cancer vaccines. However, by using viruses, tumorassociated antigen vaccines are able to help the immune system recognize malignant cells, which eliminates the need to isolate antigens. Virus-based vaccines deliver recombinant DNA in a mutated virus that is designed to contain the target antigen within their genome. These mutated virus vaccines have been shown to be more potent in stimulating an immune response in comparison to proteins and peptides (Pardoll, 2002).

In prostate cancer vaccines that utilize viruses for the delivery of treatment, research has focused on the use of modified vaccinia Arkara virus. TroVax is a current treatment that uses vaccinia Arkara, and it is currently in phase II trials. TroVax uses the human oncofetal antigen 5T4, which is expressed in high levels on the placenta and on a wide range of cancers (including both renal and prostate) but rarely is expressed in healthy tissues (Amato, Drur, Naylor, et al., 2008). A phase 2 trial using TroVax involved 27 patients with castration-resistant prostate cancer. Of these 27 patients, 14 were treated with TroVax alone and 13 received a combination of TroVax and granulocyte macrophage colony-stimulating factor. Of the 24 evaluable patients, all achieved a 5T4-specific antibody response. No grade 3 or 4 toxicities were observed, and minor incidences of myalgia, bone discomfort, lowgrade temperature elevation, and injection site irritation were experienced by patients. TroVax was shown to be effective and safe when administered alone or in combination with granulocyte macrophage colony-stimulating factor; however, no additional benefit seemed to be achieved through the addition of granulocyte macrophage colony-stimulating factor (Amato, Drur, Naylor, et al., 2008).

One study has found that patients who previously received cancer vaccines may respond for longer to docetaxel in comparison to a historical control of patients receiving docetaxel alone (Arlen, Gulley, Parker, et al., 2006). An active multi-center trial is evaluating progressionfree survival in 80 patients with metastatic castration-resistant prostate cancer receiving 10 cycles of docetaxel with or without TroVax (Oxford BioMedica \& MedSource). This trial is expected to conclude in 2016. 
More recently in pre-clinical murine models, a vaccine has been developed that destroys prostate cancer in by producing antigens that attack the prostate tumor cells. By inserting a healthy prostate tissue into a mutated vesicular stomatitis virus, researchers are able to stimulate $T$ cells to attack malignant cells. Researchers found that $T$ cells only attacked the malignant cells and left the healthy tissue unaffected, and no trace of auto-immune disease was found in the mice that received the vaccine. Clinical trials in humans for this approach are expected to begin within two years.

\section{Renal cell carcinoma}

Early stage renal cell carcinoma is treated with nephrectomy; however, 20-30\% of patients continue to develop metastatic lesions (Godley \& Taylor, 2001). Once metastatic lesions have developed, or if distant metastases are already present in nephrectomized renal cell carcinoma patients, patients' prognosis is poor with a median survival of 7 to 11 months. In patients at high risk for progression, adjuvant therapy fails to be effective, and in patients with advanced renal cell carcinoma, cytotoxic chemotherapy and radiotherapy are ineffective while interleukin-2 or interferon-alpha only elicit minimal responses $(10-15 \%$ of patients) (Amato, 2000, Bukowski, 2001). The low effectiveness and high toxicity profiles associated with current therapies for advanced renal cell carcinoma creates the need for more effective, yet safer, treatment options. Vaccine development for renal cell carcinoma proves to be promising with currently one vaccine obtaining Food and Drug Administration approval to date and a few other drugs entering phase II/III trials. Current vaccine treatments for renal cell carcinoma focus on heat shock proteins, viral vector-based immunotherapy, dendritic cells, and other tumor cells in combination with lysates.

\subsection{Heat shock proteins}

Heat shock proteins are a set of proteins that are expressed when the cells are exposed to higher temperatures. The genes that encode heat shock proteins were inadvertently identified in fruit flies exposed to high temperatures, but these genes, and the proteins that encode them, are present in all cells in all forms of life and in a variety of intracellular locations. Heat shock proteins have two properties of interest. First, they chaperone peptides, and second, they interact with antigen presenting cells in such a manner that leads to the presentation of heat shock protein-chaperoned peptides by the major histocompatibility complex class I molecules of antigen presenting cells. This has brought researchers to the following conclusions: (1) heat shock proteins chaperoning peptides is an essential part of the mechanism through which major histocompatibility complex class I molecules are charged, (2) heat shock protein-peptide complexes, rather than intact antigens, are responsible for antigens transfer during cross-presentation or cross-priming, and (3) heat shock protein-peptide complexes provide a distinct antigenic fingerprint for specific cancer tissues, which can be utilized in the development of cancer therapies. Most research focuses on GP96 (GRP94) and calreticulin, which are found in the endoplasmic reticulum, and the cystolic proteins HSP70 and HSP90.

Human heat shock protein-peptide complexes purified from tumor cells or reconstituted in vitro have shown effectiveness in mediating antigen-specific re-presentation of heat shock protein-chaperoned peptides and subsequent stimulation of CD4+ and CD8+ T cells. The 
first human clinical study with autologous heat shock proteins was conducted by Janetzki et al. in 16 patients with advanced malignancies. Each patient received $25 \mu \mathrm{g}$ subcutaneous injection of tumor-derived HSPPC-96 (vitespen) once weekly for four weeks (Janetzki, Palla, Rosenhauer, et al., 2000). Blood samples recovered from patients revealed the CD8+ restrictor response against autologous tumor in six out of 12 patients whose responses could be tested. Post-vaccination stabilization of disease for three to seven months was observed in four patients. One patient with hepatocellular carcinoma was observed to have necrosis of over $50 \%$ of the tumor coincident with vaccination. Interestingly, this patient had synchronous liver metastasis of a different primary tumor that did not respond to the vaccine prepared from her primary liver tumor. No evidence of significant toxicity associated with heat shock protein vaccine administration was observed in any patient in the study. The authors concluded there were signs of clinical responses and showed that a T-cell reaction could be generated in a fraction of patients.

A phase I study evaluated renal cell carcinoma patients treated with vitespen (Amato, Murray, Wood, et al., 1999). Patients received $2.5 \mu \mathrm{g}, 25 \mu \mathrm{g}$, or $100 \mu \mathrm{g}$ dose of autologous tumor-derived GP96 vaccine weekly for four weeks with a follow up dose at 12 or 20 weeks if the tumors showed stabilization or regression. Of the 16 patients in the $25 \mu \mathrm{g}$ cohort, one patient achieved complete response, three patients achieved partial response, and three patients achieved prolonged stabilization of disease ( $\geq 52$ weeks). A second phase II study confirmed the results (Assikis, Dallani, Pagliaro, et al., 2003). Sixty metastatic renal cell cancer patients received $25 \mu \mathrm{g}$ of HSPPC-96 weekly for four weeks and then biweekly until progression. A median of 18 weeks for progression free survival in combination with no serious adverse events observed makes HSPPC-96 a promising agent for disease stability.

Another study evaluated time to progression and response rate of autologous vitespen administered with or without interleukin 2 in metastatic renal cell carcinoma patients (Jonasch, Wood, Tamboli, et al., 2008). Patients received treatments weekly for four weeks after surgery followed by two injections biweekly. Of the 60 evaluable patients, two demonstrated complete response, two achieved partial response, seven achieved stable response, and 33 had disease progression. Two of the patients who were treated with the vaccine alone achieved disease stabilization when interleukin 2 was added to the treatment regimen. Most patients experienced no discernable benefit from treatment that included vitespen; however, use of vitespen in combination with immunoregulatory agents may have enhance the efficacy.

As a result of these findings, a randomized, multicenter phase III trial in renal cell carcinoma patients comparing adjuvant vaccination with vitespen was conducted (Wood, Srivastava, Bukowski, et al., 2008). After a median follow up of 1.9 years in the intent to treat population, recurrence was reported in $37.7 \%$ patients in the vaccine group and $39.8 \%$ of patients in the observation group indicating that recurrence-free survival was not significantly improved with the vaccine. Further research is now being done to explore whether vitespen improves recurrence-free survival in patients with earlier stage disease. Vitespan was approved in 2008 in Russian as an adjuvant therapy to treat renal cell carcinoma, and it's currently on the U.S. Food and Drug Administration's fast track for approval. 


\subsection{Viral vector-based immunotherapy}

Treatment options for advanced metastatic disease, particularly in renal cancer, are highly toxic with few clinical benefits. Researchers are focusing on new options that produce therapeutic potential while providing a favorable toxicity profile. The use of viral vectors has been explored to promote an immune response against target antigens. The primary focus of viral vectors is identifying optimal tumor-associated antigens and finding a suitable delivery system. Optimal tumor-associated antigens would show minimal expression in normal tissues but homogenous, high-level expression on tumors. Additional, optimal tumor-associated antigens would not only attack tumors but also actively interfere with tumorigenesis.

MVA-5T4 represents a compelling therapeutic option for certain types of advanced disease. More than 700 doses of MVA-5T4 have been given to humans, eliciting potent, sustained immune responses in $95 \%$ of the more than 200 patients tested (Amato, Karediy, Cao, et al., 2007). All studies have shown that MVA-5T4 has been safe and well-tolerated, resulting only in minor flu-like symptoms and mild reactions at the injection site. Researchers are studying the use of MVA-5T4 on metastasized cancers that have proved unresponsive to conventional systemic cytotoxic chemotherapy.

MVA-5T4 has been assessed in conjunction with both high-dose and low-dose interleukin 2 therapy. In a high-dose study in which patients received MVA-5T4 injections at three-week intervals along with 600,000IU/ kg interleukin 2 at weeks three, six, nine, and 12 (Kaufman, Taback, Sherman, et al., 2009). The results attributed a large number of adverse events to high-dose interleukin 2, but only two events (grade I fevers) to MVA-5T4, indicating that the regimen is safe and well tolerated in this population of patients. All patients developed 5T4specific antibody responses and 13 patients had an increase in 5T4-specific T cell responses. The baseline frequency of $\mathrm{T}$ regulatory cells was elevated in all patients, those with stable disease showed a trend toward increased effector CD8+ T cells and a decrease in $\mathrm{T}$ regulatory cells. Although vaccination with MVA-5T4 did not improve the objective response rates of interleukin 2 therapy but did result in stable disease associated with an increase in the ratio of 5T4-specific effector to regulatory T cells in selected patients.

The low-dose studies further validate the efficacy of MVA-5T4 in combination with lowdose interleukin 2 and indicate that clear-cell renal cell carcinoma patients appear more likely to respond to combination therapy. To validate the efficacy of MVA-5T4 in combination with low-dose interleukin 2 in addition to determine the safety, immunological and clinical efficacy has been completed (Amato, Shingler, Naylor, et al., 2008). Twenty-five patients with metastatic renal cell carcinoma were treated with MVA-5T4 plus low-dose interleukin 2. MVA-5T4 was well-tolerated with no serious adverse events attributed to vaccination. Of 25 intent-to-treat patients, 21 (84\%) mounted 5T4-specific antibody responses. Two patients showed a complete response for $\geq 36$ months and one a partial response for 12 months. Six patients had disease stabilization from six to 21 months. Median progression free survival and overall survival were 3.37 months (range 1.50-24.76) and 12.87 months (range 1.9- $\geq 24.76$ ), respectively. A statistically significant relationship was detected between the magnitude of the 5T4-specific antibody responses and progression free survival and overall survival. The authors had concluded that MVA-5T4 in combination with interleukin 2 was safe and well-tolerated in all patients. The high frequency of 5T4-specific 
immune responses and good clinical response rate were encouraging, and support the continued testing of MVA-5T4 vaccine in renal cancer patients.

Another approach in vaccine development for metastatic renal cell carcinoma is MVA-5T4 in combination with interferon-alpha. In one trial, 28 patients with metastatic renal cell carcinoma were treated with MVA-5T4 alone and in combination with interferon-alpha for the purpose of determining safety, immunological, and clinical efficacy (Amato, Shingler, Goonedwardena, 2009). The vaccine was well-tolerated with no serious adverse events. Of the 23 evaluable patients, 22 mounted 5T4-specific antibody and/or cellular responses. One patient treated with MVA-5T4 plus interferon-alpha showed a partial response for 12 months, whereas an additional 14 patients (seven receiving MVA-5T4 plus interferon-alpha and seven receiving MVA-5T4 alone) showed periods of disease stabilization ranging from 1.73 to 9.60 months. Median progression free survival and overall survival for all intent-totreat patients was 3.8 months (range 1-11.47) and 12.1 months (range 1-27), respectively. MVA-5T4 administered alone or in combination with interferon-alpha was well tolerated in all patients. Despite the high frequency of 5T4-specific immune responses, it is not possible to conclude that patients were receiving clinical benefit. The immunological results were encouraging and the authors warrant further investigation. An open-label phase I/II trial administered TroVax alongside interferon-alpha to 11 patients with metastatic renal cell carcinoma. Treatment was well tolerated with no serious adverse events, and all patients demonstrated 5T4-specific antibody response. Overall median time to progression was longer than interferon-alpha when administered alone (Hawkins, Macdermott, Shablak, et al., 2009).

The TroVax renal immunotherapy survival trial (TRIST) was a randomized, placebocontrolled phase III study that investigated MVA-5T4 added to first-line standard of care to evaluate survival of patients with metastatic clear-cell renal cell carcinoma. Seven hundred thirty-three patients were recruited, and received a median of eight MVA-5T4 vaccinations (Amato, Hawkins, Kaufman, et al., 2010). The standard of care consisted of interleukin 2 in $24 \%$, interferon-alpha in $51 \%$, and sunitinib in $25 \%$ in each treatment arm. Results demonstrated that MVA-5T4 was well-tolerated and administered alongside IL-2, IFN-a, and sunitinib. No significant differences in overall survival were observed in the two treatment arms. Exploratory analyses found patients received significant benefit from this vaccine based on certain pretreatment hematologic factors.

As a result of the TRIST trial, a surrogate for 5T4 response was constructed (immune response surrogate). Out of 733 patients, 590 were assessed for immune response. Patients with 5T4 antibody response had an associated longer survival within the MVA-5T4 treated group. The immune response surrogate was constructed and shown to be a significant predictor of treatment benefit. The derivation of the immune response surrogate initiated an exploratory, retrospective analysis, which could have important implications for the development and use of MVA-5T4 vaccine (Harrop, Shingler, McDonald, et al., 2011).

\subsection{Dendritic cells}

Dendritic cell vaccines are a promising option for cancer vaccine development. Dendritic cell vaccines have been evaluated in several clinical studies of patients with advanced renal cell carcinoma. 
In one study by the University of Innsbruck in Austria, isolated dendritic cells and administered three consecutive monthly intravenous infusions in seven patients. Results demonstrated that the treatment was well-tolerated with moderate fever as the only side effect. Immunological response was achieved, but only one patient achieved a partial clinical response (Höltl, Rieser, Papesh, et al., 1999, Rieser, Ramoner, Holtl, et al., 2000).

A second study used a hybrid vaccine of allogeneic dendritic cells and irradiated autologous tumor cells in 17 patients with renal cell carcinoma. Patients received the vaccine by injection followed by a second injection six weeks later. Patients who demonstrated no evidence of disease progression received further booster injections every three months. The vaccine was well tolerated with mild to moderate fever and tumor pain as the only adverse events observed. After 13 months, four patients had rejected all metastatic tumor lesions, and an additional two patients demonstrated a mass reduction of more than $50 \%$ (Kugler, Stuhler, Walden, et al., 2006). Of interest, the dendritic cell hybrid vaccine induced cytotoxic $\mathrm{T}$ cells reactive with mucin1 tumor-associated antigen - these results need to be further confirmed in larger, randomized trials.

Tumor-associated antigens can also be applied to the surface of cell-sized microspheres and then used as an immunogen. In a phase I/II study, a vaccine consisting of tumor cell membrane protein attached to 10 million microspheres was administered to patients following palliative resection of metastatic renal cell carcinoma or melanoma (Okazaki, Mescher, Curtsinger, et al., 2002). The vaccine was given alone, in combination with cyclophosphamide, or in combination with cyclophosphamide and interleukin 2 . Two doses of vaccine were administered at four-week intervals. Cyclophosphamide was given one week before the first vaccine dose in order to decrease $\mathrm{T}$ regulatory cells, whereas interleukin 2 was administered for one week starting five days after each vaccination in order to increase immunogenicity. The first 13 patients in the study included four with metastatic renal cell carcinoma. One patient with resected metastatic renal cell carcinoma who was treated with the vaccine plus cyclophosphamide and interleukin 2 remained free of disease at six months after therapy.

Another study used a vaccine that contained electrofused allogeneic dendritic cells and autologous tumor-derived cells in patients with metastatic renal cell carcinoma. The tumors were processed into a single-cell suspension and cryopreserved. Dendritic Cells were generated from peripheral blood mononuclear cells isolated from volunteers and cultured with granulocyte macrophage colony-stimulating factor, interleukin 4 , and tumor necrosis factor-alpha. Dendritic cells were then fused to the patient-derived renal cell carcinoma with serial electrical pulses. The patients received up to three vaccinations. Twenty-four patients underwent this approach. There was no evidence of toxicity related to the vaccine. Two patients demonstrated a partial response. Forty-eight percent of the patients demonstrated an immunological response with an increase in CD4 and/or CD8+ T-cell expression. The authors concluded that this approach was feasible and tolerable. Further development is under way in combination with granulocyte macrophage colony-stimulating factor (Avigan, Vasir, George, et al., 2007).

\section{Bladder cancer}

Approximately $70 \%$ to $80 \%$ of patients diagnosed with bladder cancer present with superficial, noninvasive malignancies, which can often be cured. Deeply invasive 
malignancies can sometimes be cured by surgery, radiation therapy, or a combination that includes chemotherapy. Patients with invasive tumors confined to bladder muscles after cystectomy experience a $75 \%$ five-year progression-free survival rate. Patents with deeply invasive tumors experience a $30 \%$ to $50 \%$ 5-year survival rate following cystectomy (Quek, Stein, Nichols, et al., 2005).

\subsection{Vaccine approaches}

Less attention has been paid on the development of a bladder cancer vaccine. Most treatment for bladder cancer has focused on the use of Bacille Calmette-Guerin following resection. Multiple studies have established that treating bladder cancer with a complete transurethral resection or fulguration of superficial disease followed by Bacille CalmetteGuerin prophylaxis significantly reduces recurrence and prolongs disease-free progression in comparison to transurethral resection alone (Lamm, 1992). Recurrence is reduced by $7 \%$ to $65 \%$ (Krege, Giani, Meyer, et al., 1996). One study of patients with T1 lesions who were treated with Bacille Calmette-Guerin following transurethral resection found that $91 \%$ of patients were free of tumor recurrence for a mean follow up of 59 months. Sixty-nine percent of these remained free of disease after the initial therapy, and another $22 \%$ underwent an additional transurethral resection followed by Bacille Calmette-Guerin before becoming disease free (Cookson \& Sarosday, 1992). Bacille Calmette-Guerin following transurethral resection has proved to be effective in treating bladder cancer.

Additional studies are currently underway to determine alternative treatments for patients who fail resection and Bacille Calmette-Guerin. In preclinical studies, a conformulation of interleukin-12 with chitosan was well tolerated and efficient at curing mice with superficial bladder cancer, and an antitumor response was generated in mice receiving this conformulation, providing complete protection against intravesical tumor rechallenge (Zaharoff, Hoffman, Hooper, et al., 2009).

Two active studies are expected to near completion within the next two years. One phase II study by Iwate Medical University is examining the use of peptides in bladder vaccinations following surgery (Iwate Medical University). The investigators are focusing on human leukocyte antigen- $A^{*} 2402$ restricted epitope peptides, which when stimulated were found to produce a strong interferon-g production. The study will determine feasibility, cytotoxic $\mathrm{T}$ cell response, CD8+ population, the change in level of regulatory $\mathrm{T}$ cells, and overall survival. The study is expected to conclude in November 2011. Another active study (phase I/II) is focusing on developing a vaccine for metastatic bladder cancer to induce a cellular immune response involving both $\mathrm{CD} 4+$ and CD8+ T cell populations (Vaxil Therapeutics Ltd.). The study will determine the feasibility and safety of administering ImMucin peptide combined with human chorionic gonadotropin-colony stimulating factor as well as the efficacy of treatment. The study is expected to conclude in September 2012.

An active study is using CDX-1307, which stimulates an immune response against a protein called human chorionic gonadotropin-beta, on patients with muscle invasive bladder cancer given before or after cystectomy (Celldex Therapeutics.). This protein, which is made by several types of cancers including bladder cancer, has been associated with shorter times to development of metastases and reduced survival in bladder cancer. The vaccine in this study is expected to cause the immune system to attack human chorionic gonadotropin- 
beta-producing bladder cancer cells to kill or terminate metastasis. This study is expected to conclude in October 2017.

\section{Conclusion}

The key to making vaccine therapy a viable option for the treatment of cancer is in identifying the subject of patients for which a specific vaccine therapy would be most beneficial. Patients who have minimal disease or are in high-risk adjuvant settings are most likely to benefit from vaccine therapy as they are least likely to increase tumor suppression of the immune system. Patients with advanced disease who are more likely to have significant tumor immune suppression will probably benefit more from the use of vaccines in combination with other forms of treatment. Additionally, the use of vaccines in combination with other forms of immunotherapy may prove to be more effective in treating genitourinary cancers. One such form of immunotherapy is sunitinib, which preliminary data has shown the potential in decreasing $T$ regulatory cells.

Cancer vaccines are promising for the treatment of genitourinary cancers, including prostate, renal cell carcinoma, and bladder. They offer immunogenic response with a low toxicity profile, making them attractive options for patients with advanced stages of cancer. In renal cell carcinoma, heat shock protein-based vaccines have demonstrated effectiveness in earlier stage renal cell carcinoma patients, but manufacturing the vaccine is timeconsuming. MVA-5T4 has high potential as a viable vaccine therapy for metastatic renal cell carcinoma, and it is well tolerated in combination with other therapies. However, more information about tumor-associated antigens for renal cell carcinoma is needed before taking the next step forward into making viral-based vaccine therapy a viable option. The TRIST trial on TroVax helped form an exploratory analysis, which has the potential to make significant advances in the development and use of MVA-5T4 vaccines.

In prostate cancer vaccines, the identification of specific tumor-associated antigens and research into related immunogenic treatments is bringing us closer to developing effective tumor-specific vaccines that are only cytotoxic to malignant cells. However, further research on the molecular and cellular mechanism that regulate antitumor immunity and the malignant process will allow for further development of vaccines using more potent prostate specific antigens and new protocols to use as vaccines alone or in combination with adjuvant therapies.

Future studies for genitourinary cancer vaccines will need to be refined by optimizing patient selection and using tumor-response criteria that are specific to trials of immunotherapy. Currently, vitespen is on a fast track for Food and Drug Administrationapproval in the treatment for renal cell carcinoma vaccine with further research being conducted in advanced phase clinical trials. One prostate cancer vaccine has already been approved by the Food and Drug Administration, and two more prostate cancer vaccines (TroVax and PROSTVAC) are in advanced stage trials with PROSTVAC currently seeking Food and Drug Administration approval. No vaccine currently is approved for the treatment of bladder cancer. Further research needs to be conducted in the way of bladder cancer vaccines although bladder cancer is less common and has better prognosis using current treatment methods. 


\section{References}

Amato RJ. (2000). Chemotherapy for renal cell carcinoma. Seminars in Oncology, Vol. 27, No. 2 (April 2000), pp. 177-86

Amato R.J., Drury N., Naylor S., Jac J., Saxena S., Cao A., Hernandez-McClain J., \& Harrop R. (2008). Vaccination of prostate cancer patients with modified vaccinia Ankara delivering the tumor antigen 5t4 (TroVax). Journal of Immunotherapy, Vol. 31, No. 60, (August 2008), pp. 577-585.

Amato R., Hawkins R., Kaufman H., Thompson J., Tomczak P., Szczylik C., McDonald M., Eastty S., Shingler W., de Belin J., Goonewardena M., Naylor S., \& Harrop R. (2010). Vaccination of Metastatic Renal Cancer Patients with MVA-5T4: A randomized, double blind, placebo-controlled phase III study. Clinical Cancer Research, Vol. 16, No. 22, (November 2010), pp. 5539-47

Amato R., Karediy M., Cao A., et al., (2007). Phase II trial to assess the activity of MVA 5T4 (TroVax) alone versus MVA 5T4 plus granulocyte macrophage colony-stimulating factor in patients with progressive hormone refractory prostate cancer, Journal of Clinical Oncology, Proceedings of the 2007 ASCO Annual Meeting, 2007;25:241s

Amato R., Murray L., Wood L., Savary C., Tomasovic S., \& Reitsma D. (1999). Active specific immunotherapy in patients with renal cell carcinoma (RCC) using autologous tumor derived heat shock protein-peptide complex-96 (HSPP-96) vaccine, Proceedings of American Society of Clinical Oncology, 18:322a

Amato R., Shingler W., Goonedwardena M., de Belin J., Naylor S., Jac J., Willis J., Saxena S., Hernandez-McClain J., \& Harrop R. (2009). Vaccination of Renal Cell Cancer Patients with Modified Vaccinia Ankara Delivering the Tumor Antigen 5T4 (TroVax) Alone or Administered in Combination with Interferon- $\alpha$ (IFN-a): A Phase 2 Trial, Journal of Immunotherapy, Vol. 32, No. 7, (September 2009), pp. 765-72

Amato R., Shingler W., Naylor S., Jac J., Willis J., Saxena S., Hernandez-McClain J., \& Harrop R. (2008). Vaccination of Renal Cell Cancer Patients with Modified Vaccinia Ankara Delivering Tumor Antigen 5T4 (TroVax) Administered with Interleukin 2: A Phase II Trial, Clinical Cancer Research, Vol. 14, No. 22, (November 2008), pp. 7504-10

Arlen, P.M., Gulley, J.L., Parker, C., Skarupa L., Pazud M., Panicali, D., Beetham, P., Tsang K. Y., Grosenbach D.W., Feldman J., Steinberg S.M., Jones E., Chen C., Marte J., Schlow J., \& Dahut W. (2006). A randomized phase II study of concurrent docetaxel plus vaccine versus vaccine alone in metastatic androgen independent prostate cancer. Clin Cancer Research, Vol. 12, No. 4, (February 2006), pp. 1260-1269

Assikis V.J., Dallani D., Pagliaro L., Wood, C., Perez C., Logothetis C., Papandreou C., Hawkins E.S., \& Srivastava P.K. (2003). Phase II study of an autologous tumor derived heat shock protein-peptide complex vaccine (HSPPC-96) for patients with metastatic renal cell carcinoma (mRCC), Proceedings of American Society of Clinical Oncology, 2003;22:386

Avigan D.E., Vasir B., George D.J., Oh W.K., Atkins M.B., McDermott D.F., Kantoff P.W., Figlin R.A., Vasconcelles M.J., Xu Y., Kufe D., \& Bukowski R.M. (2007). Phase I/II study of vaccination with electrofused allogeneic dendritic cells/autologous tumorderived cells in patients with stage IV renal cell carcinoma, Journal of Immunotherapy, Vol. 30, No. 7, (October 2007), pp. 749-61 
Banchereau, J., \& Steinman, R.M. (1998). Dendritic cells and the control of immunity. Nature, Vol. 392, No. 6673, (March 1998), pp. 245-252

Bukowski RM. (2001). Cytokine therapy for metastatic renal cell carcinoma. Seminars in Urologic Oncology, Vol. 19, No. 2 (May 2001), pp. 148-54

Celldex Therapeutics. A phase II, open-label study of the CDX-1307 vaccine regimen as neoadjuvant and adjuvant therapy in patients with newly diagnosed muscleinvasive bladder cancer expressing hCG- $\beta$. In: ClinicalTrials.gov [Internet]. Bethesda (MD): National Library of Medicine (US). 2000- [cited July 2011]. Available from: http://clinicaltrials.gov/show/NCT01094496 NLM Identifier Number : NCT01094496.

Cookson M.S., \& Sarosday M.F. (1992). Management of stage T1 superficial bladder cancer with intravesical bacillus Calmette-Guerin therapy. The Journal of Urology, Vol. 148, No. 3, (September 1992), pp. 797-801

Fuessel, S., Meye, A., Schmitz, M., Zastrow S., Linné C., Richter K., Löbel B., Hakenberg O.W., Hoelig K., Rieber E.P., \& Wirth M.P. (2006). Vaccination of hormonerefractory prostate cancer patients with peptide cocktail-loaded dendritic cells: results of a phase I clinical trial. Prostate, Vol. 66, No. 8, (June 2006), pp. 811-821.

Feyerabend S., Stevanovic S., Gouttefangeas C., Wernet D., Hennenlotter J., Bedke J., Dietz K., Pascolo S., Kuczyk M., Rammensee H.G., \& Stenzl A. (2009). Novel multipeptide vaccination in HLA-A2+ hormone sensitive patients with biochemical relapse of prostate cancer. Prostate, Vol. 69, No. 9, (June 15), pp. 917-927.

Godley, PA., \& Taylor M. (2001). Renal cell carcinoma. Current Opinion in Oncology, Vol. 13, No. 3 (May 2001), pp. 199-203

Harrop R., \& Ryan M. (2005). Active treatment of murine tumors with a highly attenuated vaccinia virus expressing the tumor associated antigen 5T4 (TroVax) is CD4+ T cell dependent and antibody mediated, Cancer Immunology, Immunotherapy, Vol. 55. No. 9, (September 2005), pp. 1081-90

Harrop R., Shingler W.H., McDonald M., Treasure P., Amato R.J., Hawkins R.E., Kaufman H.L., de Belin J., Kelleher M., Goonewardena M., \& Naylor S. (2006). MVA-5T4induced immune responses are an early marker of efficacy in renal cancer patients. Cancer Immunolology, Immunotherapy, Vol. 60, No. 6, (June 2011), pp.829-37

Hawkins R.E., Macdermott C., Shablak A., Hamer C., Thistlethwaite F., Drury N.L., Chikoti P., Shingler W., Naylor S., \& Harrop R. (2009). Vaccination of patients with metastatic renal cancer with modified vaccinia Ankara encoding the tumor antigen 5T4 (TroVax) given alongside interferon-alpha. Journal of Immunotherapy, Vol. 32, No. 4, (May 2009), pp.424-429

Higano C.S., Schellhammer P.F., Small E.J., Burch P.A., Nemunaitis J., Yuh L., Provost N., \& Frohlich M.W. (2009). Integrated data from 2 randomized, double-blind, placebocontrolled, phase 3 trials of active cellular immunotherapy with sipuleucel-t in advanced prostate cancer. Cancer, DOI: 10.1002/cnrc. 24429 August 15, 2009

Höltl L., Rieser C., Papesh C., Ramoner R., Herold M., Klocker H., Radmayr C., Stenzl A., Bartsch G., \& Thurnher M. (1999). Cellular and humoral immune responses in patients with metastatic renal cell carcinoma after vaccination with antigen pulsed dendritic cells, Journal of Urology, Vol. 161, No. 3 (March 1999), pp. 777-82 
Iwate Medical University. Phase II Study of Bladder Cancer Using Novel Tumor Antigens for Prevention of the Recurrence for Bladder Cancer After TUR-Bt. In: ClinicalTrials.gov [Internet]. Bethesda (MD): National Library of Medicine (US). 2000- [cited July 2011]. Available from: http://clinicaltrials.gov/ct2/show/ NCT00633204 NLM Identifier Number: NCT00633204

Janetzki S., Palla D., Rosenhauer V., Lochs H., Lewis J.J., \& Srivastava P.K. (2000). Immunization of cancer patients with autologous cancer-derived heat shock protein GP96 preparations: a pilot study. International Journal of Cancer, Vol. 88, No. 2, (October 2000), pp. 232-8

Johnson, L.E., Frye, T.P., Chinnasamy, N., Chinnasamy, D., \& McNeel D.G. (2007). Plasmid DNA vaccine encoding prostatic acid phosphatase is effective in eliciting autologous antigen-specific CD8+ T cells. Cancer Immunolology, Immunotherapy, Vol. 56, No. 6, (June 2007), pp. 885-895

Jonasch E., Wood C., Tamboli P., Pagliaro L.C., Tu S.M., Kim J., Srivastava P., Perez C., Isakov L., \& Tannir N. (2008). Vaccination of metastatic renal cell carcionma patients with autologous tumour-derived vitespen vaccin : clinical findings. British Journal of Cancer, Vol. 98, (March 2008), pp. 1336-1341

Kantoff, P.W., Schuetz, T.J., Blumenstein, B.A., Glode M., Bilhartz D.L., Wyand M., Manson K., Panicali D.L. Laus R., Schlom J., Dahut W.L., Arlen P.M., Gulley J.L., Godfrey W.R. (2010). Overall survival analysis of a phase II randomized controlled trial of a poxviral-based PSA-targeted immunotherapy in metastatic castration-resistant prostate cancer. Journal of Clinical Oncology, Vol. 28, No. 7, (March 2010), pp. 10991105

Kaufman H.L., Taback B., Sherman W., Kim D.W., Shingler W.H., Moroziewicz D., DeRaffele G., Mitcham J., Carroll M.W., Harrop R., Naylor S., \& Kim-Schulze S. (2009). Phase II trial of Modified Vaccinia Ankara (MVA) virus expressing 5T4 and high dose Interleukin-2 (IL-2) in patients with metastatic renal cell carcinoma. Journal of Translational Medicine., Vol. 7, No. 7:2, (January 2009).

Kottke, T., Errington, F., Pulido, J., Galivo, F., Thompson, J., Wongthida, P., Diaz, R.M., Chong, H., Ilett, E., Chester, J., Pandha, H., Harrington, K., Selby, P., Melcher, A., \& Vile, R. (2011). Broad antigenic coverage induced by vaccination with virus-based cDNA libraries cures established tumors. Nature Medicine, (June 2011), DOI: $10.1038 / \mathrm{nm} .2390$

Krege S., Giani G., Meyer R., Otto T., \& Rubben H. (1996). A randomized multicenter trial of adjuvant therapy in superficial bladder cancer: transurethral resection plus bacillus Calmette-Guerin. The Journal of Urology, Vol. 156, No. 3, (September 1996), pp. 962-6

Kugler A, Stuhler G, Walden P, et al., Regression of human metastatic renal cell carcinoma after vaccination with tumor cell-dendritic cell hybrids, Nat Med, 2000;6:332-6

Lamm DL. (1992). Long-term results of intravesical therapy for superficial bladder cancer. The Urologic Clinics of North America, Vol. 19, No. 3., (August 1992), pp. 573-80

McNeel D.G., Dunph ,E.J., Davies J.G., Frye T.P., Johnson L.E., Staab M.J., Horvath D.L., Straus J., Alberti D., Marnocha R., Liu G., Eickhoff J.C., \& Wilding G. (2009). Safety and immuniological efficacy of a DNA vaccine encoding prostatic acid phosphatase in patients with stage D0 prostate cancer. Journal of Clinical Oncology, Vol. 27, No. 25, (September 2009), pp. 4047-4054 
Okazaki I., Mescher M., Curtsinger J., Bostrum N., Fautsch S., \& Miller J. (2002). An autologous large multivalent immunogen (LMI) vaccine for the treatment of metastatic melanoma and renal cell carcinoma, Proceedings of American Society of Clinical Oncology, 2002;21:20a

Oxford BioMedica \& MedSource. A Randomized Phase II Study to Assess the Activity of TroVax ${ }^{\circledR}$ (MVA-5T4) Plus Docetaxel Versus Docetaxel Alone in Subjects With Progressive Hormone Refractory Prostate Cancer. In: ClinicalTrials.gov [Internet]. Bethesda (MD): National Library of Medicine (US). 2000- [cited July 2011]. Available from: http://clinicaltrials.gov/ct2/show/NCT01194960 NLM Identifier Number: NCT01194960

Pardoll, D.M. (2002). Spinning molecular immunology into successful immunotherapy. Nature Reviews. Immunology, Vol 2, No. 4, (April 2002), pp. 227-238

Quek M.L., Stein J.P., Nichols P.W., Cai J., Miranda G., Groshen S., Daneshmand S., Skinner E.C., \& Skinner D.G. (2005). Prognostic significance of lymphovascular invasion of bladder cancer treated with radical cystectomy. Journal of Urology, Vol. 174, No. 1 (July 2005), pp. 103-6

Rieser C., Ramoner R., Holtl L., Rogatsch H., Papesh C., Stenzl A., Bartsch G., \& Thurnher M. (1999). Mature dendritic cells induce T-helper type-1-dominant immune responses in patients with metastatic renal cell carcinoma, Urologia Internationalis, Vol. 63, No. 3, (1999), pp. 151-9

Tamura Y., Peng P., Liu K., Daou M., \& Srivastava, P.K. (1997). Immunotherapy of tumors with autologous tumor-derived heat shock protein preparations, Science, Vol., 278, (October 1997), pp.117-20

Thomas-Kaskel, A.K., Zeiser, R., Jochim, R., Robbel, C., Schultze-Seemann, W., Waller, C.F., Veelken, H. (2006). Vaccination of advanced prostate cancer patients with PSCA and PSA peptide-loaded dendritic cells induces DTH responses that correlate with superior overall survival. International Journal of Cancer, Vol. 199, No. 10, (November 2006), pp. 2428-2434.

Vaxil Therapeutics Ltd. A Novel Vaccine for the Treatment of MUC1-expressing Tumor Malignancies. In: ClinicalTrials.gov [Internet]. Bethesda (MD): National Library of Medicine (US). 2000- [cited July 2011]. Available from: http://clinicaltrials.gov/ show/NCT01232712 NLM Identifier Number: NCT01232712

Vieweg J. \& Dannul J. (2005). Technology insight: vaccine therapy for prostate cancer. Nature, Vol. 2, No. 1, (January 2005), pp. 44-51.

Waeckerle-Men Y., Allmen E.U., Fopp M., von Moos R., Böhme C., Schmid H.P., Ackermann D., Cerny T., Ludewig B., Groettrup M., \& Gillessen S. (2006). Dendritic cell-based multi-epitope immunotherapy of hormone-refractory prostate carcinoma. Cancer Immunolology, Immunotherapy, Vol. 55, No. 12, (December 2006), pp. 1524-1533

Wood C.G., Srivastava P., Bukowski R., Lacombe L., Gorelov A.I., Gorelov S., Mulders P., Zielinski H., Hoos A., Teofilovici F., Isakov L., Flanigan R., Gupta R., \& Escudier B. (2008). An adjuvant autologous therapeutic vaccine (HSPPC-96;vitespen) versus observation alone for patients at high risk of recurrence after nephrectomy for renal cell carcinoma; a multicentre, open-label, randomized phase III trial, The Lancet, Vol. 372, No. 9633, (July 2008), pp. 145-154 
Zaharoff D.A., Hoffman B.S., Hooper H.B., Benjamin C.J., Khurana K.K., Hance K.W., Rogers C.J., Pinto P.A., Schlom J., \& Greiner J.W. (2009). Intravesical immunotherapy of superficial bladder cancer with chitosan/interleukin-12. Cancer Research, Vol. 69, No. (July 2009), pp. 6192-6199 


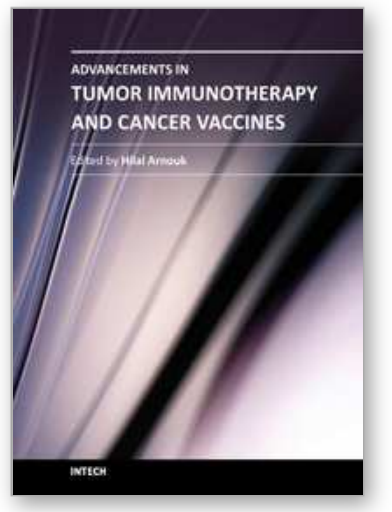

\author{
Advancements in Tumor Immunotherapy and Cancer Vaccines \\ Edited by Dr. Hilal Arnouk
}

ISBN 978-953-307-998-1

Hard cover, 218 pages

Publisher InTech

Published online 03, February, 2012

Published in print edition February, 2012

Harnessing the potential of the human body's own immune system to attack malignant tumor cells has been the goal of many scientific investigators in recent years, with advances in cancer biology and immunology enabling cancer immunotherapy to become a reality. World-class bench and clinical researchers have joined forces to collaborate and review current developments and trends in cancer immunology for the purposes of this book, and the result is a promising review of contemporary clinical treatments. In each chapter the authors present the scientific basis behind such therapeutic approaches, including cancer vaccines with special focus on prostate cancer, melanoma and novel approaches utilizing both innate and adaptive immune responses.

\title{
How to reference
}

In order to correctly reference this scholarly work, feel free to copy and paste the following:

Robert J. Amato and Mika Stepankiw (2012). Vaccine and Cancer Therapy for Genitourinary Tumors, Advancements in Tumor Immunotherapy and Cancer Vaccines, Dr. Hilal Arnouk (Ed.), ISBN: 978-953-307998-1, InTech, Available from: http://www.intechopen.com/books/advancements-in-tumor-immunotherapyand-cancer-vaccines/vaccine-and-cancer-therapy-for-genitourinary-tumors

\section{INTECH}

open science | open minds

\section{InTech Europe}

University Campus STeP Ri Slavka Krautzeka 83/A 51000 Rijeka, Croatia Phone: +385 (51) 770447 Fax: +385 (51) 686166 www.intechopen.com

\section{InTech China}

Unit 405, Office Block, Hotel Equatorial Shanghai No.65, Yan An Road (West), Shanghai, 200040, China 中国上海市延安西路65号上海国际贵都大饭店办公楼 405 单元 Phone: +86-21-62489820

Fax: +86-21-62489821 
(C) 2012 The Author(s). Licensee IntechOpen. This is an open access article distributed under the terms of the Creative Commons Attribution 3.0 License, which permits unrestricted use, distribution, and reproduction in any medium, provided the original work is properly cited. 